\title{
IMAGEM DE EVENTOS TURÍSTICOS: PERSPECTIVAS DO FESTIVAL BRASILEIRO DA CERVEJA, BLUMENAU - $\mathrm{SC}$
}

IMAGE OF TOURIST EVENTS: PERSPECTIVES OF THE BRAZILIAN BEER FESTIVAL, HELD IN BLUMENAU - SC

IMAGEN DE EVENTOS TURÍSTICOS: PERSPECTIVAS DEL FESTIVAL BRASILEÑO DE LA CERVEZA, BLUMENAU - SC

\section{Thiago dos Santos}

Mestre em Administração. Professor do Depto de Comunicação da FURB.

Fabrícia Durieux Zucco

Doutora em Administração. Mestre em Administração. Professora do Programa de Mestrado e Doutorado em Turismo da Únivali. Professora do Depto de Comunicação da FURB.

Camila Belli Kraus

Pesquisadora em Comunicação. Bacharel em Publicidade e Propaganda FURB.

Data de Submissão: 29/07/2014 Data de Aprovação: 19/03/2015 
RESUMO: Os festivais estão em crescimento tanto no Brasil como no mundo. Esses eventos ajudam a preservar costumes e tradições dos destinos turísticos e contribuem positivamente para imagem e economia local. Este artigo analisa a imagem do $5^{\circ}$ Festival Brasileiro da Cerveja, realizado em Blumenau, Santa Catarina, a partir da perspectiva do público que frequenta o evento. Foi utilizado como base teórico-metodológica o estudo de Deng, Li e Shen (2013), Developing a measurement scale for event image. Para o cumprimento do objetivo proposto realizou-se uma pesquisa descritiva com método quantitativo e levantamento do tipo survey. Utilizou-se como instrumento de coleta de dados um questionário estruturado, aplicado com 507 visitantes que passaram pelos quatro dias de evento em março de 2013. Por meio dos resultados da Modelagem de Equação Estrutural, verificou-se que as Fontes de Informação exercem influência sobre a Imagem de Evento. A dimensão Tema é a que melhor representa a escala de Imagem de Evento, e os Meios Digitais melhor representam as Fontes de Informação.

Palavras-chave: Eventos. Festivais. Imagem. Festival Brasileiro da Cerveja.

ABSTRACT: Festivals are growing worldwide, including in Brazil. These events help to the preserve customs and traditions of tourist destinations, as well as making a positive contribution to the image and economy of the local community. This article analyzes the image of the Brazilian Beer Festival, held in Blumenau, Santa Catarina, from the perspective of the public who attended the event. We used Deng, Li and Shen (2013) as a theoretical and methodological basis for this study, developing a scale to measure the image of the event. We developed a descriptive and quantitative analysis to accomplish our research objectives, though a questionnaire, which was administered to 507 people who visited the four-day event in March 2013. Using Structural Equation Modeling, we found that Information Sources influence the Event image. The "theme" construct proved 
to be the one that best represents the scale of the Event Image, and Digital Media proved to be the main source of information used by the public.

Key words: Events. Festivals. Image. Festival Brasileiro da Cerveja.

RESUMEN: Los festivales están en crecimiento, tanto en Brasil como en el mundo. Estos eventos ayudan a preservar las costumbres y tradiciones de los destinos turísticos y contribuyen positivamente con la imagen y la economía locales. Este artículo analiza la imagen del $5^{\circ}$ Festival Brasileño de la Cerveza, realizado en Blumenau, Santa Catarina, a partir de la perspectiva del público que asiste al evento. Se utilizó como base teórico-metodológica el estudio de Deng, Li y Shen (2013), Developing a measurement scale for event image. Para cumplir el objetivo propuesto se realizó una investigación descriptiva con método cuantitativo y análisis de tipo survey. Se utilizó como instrumento de colecta de datos un cuestionario estructurado aplicado a 507 visitantes que pasaron por los cuatro días del evento en marzo de 2013. Por medio de los resultados del Modelado de Ecuación Estructural, se verificó que las Fuentes de Información ejercen influencia sobre la Imagen del Evento. La dimensión Tema es la que mejor representa la escala de Imagen del Evento, y los Medios Digitales representan mejor a las Fuentes de Información.

Palabras clave: Eventos. Festivales. Imagen. Festival Brasileño de la Cerveza.

\section{INTRODUÇÃO}

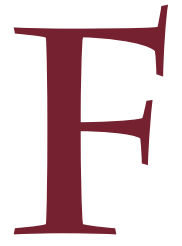

estivais, feiras e outros tipos de eventos fazem parte da economia do turismo e têm sido cada vez mais utilizados para impulsionar as atividades do setor, principalmente por causa de seu forte poder atrativo de público. Além de trazerem visitantes para a cidade, eles contribuem para promover e preservar a cultura e o patrimônio histórico. 
Conhecidos por desempenharem um papel importante em relação à cidade que os sedia, no que diz respeito tanto à imagem do destino quanto à economia local, os eventos programados são, segundo Getz (2008), fenômenos espaçotemporais e cada um é singular por causa das interações estabelecidas entre o ambiente, as pessoas e os sistemas de gestão.

Nesse contexto, os festivais são vistos por Yeoman, Robertson e Ali-Knight (2006) como oportunidades de ótimos negócios para o destino, podendo tornar-se parte das estratégias de turismo de uma cidade. De acordo com Getz (2004), eles podem ser identificados como atrações, produtores de imagens, animadores de atrativos estáticos e catalisadores de desenvolvimento.

Destacando o fato de os festivais renovarem periodicamente o fluxo de vida de uma comunidade, Quinn (2009) observa que, com uma longa trajetória histórica a incorporar as tradições de vários passados, eles têm florescido novamente na sociedade contemporânea e se proliferado de maneira notável. Essa constatação também é feita por Gürsoy, Kim e Uysal (2004) e Prentice e Andersen (2003), que enfatizam o potencial turístico dos festivais.

Na perspectiva do desenvolvimento de longo prazo, a criação de imagem é apontada por Deng, Li e Shen (2013) como um dos papéis mais importantes dos festivais, pois estes podem moldar a imagem da cidade-sede, da região ou do país e levar a uma percepção favorável como destino potencial de viagem. Os autores consideram que a percepção dos consumidores é um valioso elemento de investigação que permite capturar de forma abrangente as avaliações cognitivas e afetivas desses sujeitos e que os estudos de imagem constituem, portanto, um fluxo importante de pesquisa.

$\mathrm{Na}$ literatura do turismo, a imagem do evento tem sido menos estudada do que a imagem de destino e não se tem uma definição clara ou uma escala de medição para a imagem do evento (DENG; LI \& SHEN, 2013) - esta é normalmente discutida no contexto de patrocínio, como no caso dos estudos de Rifon, Choi, Trimble e Hairong (2004), Roy e Cornwell (2004), Schiffman e Kanuk (2010), Weeks, Cornwell e Drennan (2008), Xing e Chalip (2006). Cabe ressaltar que cada evento possui uma imagem distinta que é derivada a partir do seu conjunto único de atributos (CHIEN; CORNWELL \& STOKES, 2005). 
Diante dessas constatações e reconhecendo a relevância dos festivais - o impacto que exercem sobre as economias locais e os benefícios que geram para os destinos - , buscou-se analisar a imagem do Festival Brasileiro da Cerveja, realizado em Blumenau, Santa Catarina, a partir da percepção do público que frequenta o evento e utilizando como base teórico-metodológica o estudo de Deng, Li e Shen (2013), Developing a measurement scale for event image.

O presente estudo visa aprofundar as pesquisas no âmbito dos festivais, visto como alternativa para minimizar os impactos negativos da visitação de massa e promover melhores relações entre os visitantes e os anfitriões. Os festivais podem ainda ampliar as estações turísticas, estender a alta temporada ou, ainda, introduzir uma "nova estação" na vida de uma comunidade.

A pesquisa foi realizada durante o $5^{\circ}$ Festival Brasileiro da Cerveja, realizado em Blumenau, SC, no período de 20 a 23 de março de 2013. O festival reuniu mais de 500 rótulos de cervejas nacionais e importados, distribuídos em 67 estandes de cervejarias, de empresas consolidadas no mercado. Nesta edição, foi criado o Concurso Brasileiro da Cerveja, com a presença de cinco jurados estrangeiros e mais de 200 rótulos concorrentes. Em 2013 o festival teve um aumento de público de $25 \%$ em relação ao ano anterior. Em quatro dias de evento, 27.738 pessoas compareceram ao festival.

$\mathrm{Na}$ presente pesquisa foram utilizados 507 questionários validados distribuídos nos quatro dias do festival. Utilizou-se questionário estruturado, autopreenchível, com perguntas abertas e fechadas.

Quanto à sua organização estrutural, este trabalho se divide em cinco unidades básicas: Introdução, Marco Teórico, Metodologia, Apresentação e Discussão dos Resultados, Considerações Finais.

\section{IMAGEM DE EVENTOS}

A imagem de produtos e destinos turísticos tem sido estudada em diferentes perspectivas teóricas e multidisciplinares. De acordo com Li e Vogelsong (2006) e Martín e Bosque (2008), existem mais de 30 definições de imagem 
na literatura do turismo que fazem referência a três componentes: cognitivo, afetivo e características psicológicas.

Gwinner (1997, p. 147) define imagem do evento como "a interpretação cumulativa de significados ou associações atribuída a eventos por consumidores". Para Ferrand e Pages (1996, p. 282), é uma "construção cognitiva associando representações racionais e afetivos de um evento por uma pessoa ou um grupo".

A imagem do destino deve ser considerada um fenômeno multidimensional, que inclui não apenas crenças ou conhecimentos sobre o destino, mas também os sentimentos que os visitantes têm em relação à cidade visitada (MARTÍN \& BOSQUE, 2008).

Imagem de evento e imagem de destino podem ser categorizadas juntas, pois a forma como são percebidos pelos visitantes permite que sejam definidas como positivas ou negativas. Os autores asseveram que a matriz de ajuste de imagem do destino e do evento não pode ser considerada uma ferramenta única para moldar a imagem dos destinos. A partir de uma perspectiva estratégica de longo prazo, pode ser usada, como parte do evento, a análise de portfólio para auxiliar os gestores no momento de analisar quais eventos possuem associações positivas para a cidade e quais não melhoram e nem reforçam a imagem do destino (FLOREK \& INSCH, 2011).

A imagem do evento reflete o significado do evento para o indivíduo e pode ser caracterizada utilizando rótulos descritivos que representam uma soma de suas percepções. Esses rótulos correspondem a associações de imagem e incluem: jovem, maduro, tranquilo, aventureiro, educado, social, tradicional, exclusivo, comum, liberal, conservador e de alta classe, cerebral, atlético, artístico, orgulhoso, político. Assim, a imagem de evento pode ser pensada como um conjunto de associações de imagens (GWINNER, 1997).

Por outro lado, uma característica importante da imagem de eventos, que é semelhante à da imagem de destino e à imagem de marca, é a sua natureza dinâmica. Essa imagem não permanece na mente humana; ela varia e muda devido a uma variedade de fatores. Os autores ressaltam que a formação de imagem do evento é afetada por vários fatores, incluindo fontes de informações e fatores pessoais. As fontes de informação se referem à quantidade e à 
natureza diversa de fontes de informação às quais os indivíduos estão expostos, incluindo promoção, opiniões dos outros, relatórios de mídia, cultura popular e experiência pessoal dos turistas. Os fatores pessoais podem ser agrupados em três tipos: sociodemográficos (sexo, idade, nível de educação, ciclo de vida familiar, classe social, local de residência), fatores psicológicos (motivações, valores, estilo de vida, personalidade) e da experiência de viagens anteriores (DENG; LI \& SHEN, 2013).

\section{FESTIVAIS}

Os festivais podem ser vistos como alternativa para minimizar os impactos negativos da visitação de massa e promover melhores relações entre os visitantes e os anfitriões. Podem ampliar as estações turísticas, estender a alta estação ou ainda introduzir uma "nova estação" na vida de uma comunidade.

Yeoman et al. (2006) ressaltam que a perspectiva de desenvolvimento do turismo de eventos pela comunidade reconhece os elementos de espírito e orgulho comunitário, a cooperação, liderança, exaltação de tradições culturais, capacidade de controlar o desenvolvimento e ainda melhorias nas facilidades e conveniências sociais e de saúde.

Os festivais são celebrações culturais, e sempre ocuparam um lugar especial na sociedade. Seu papel comemorativo e suas implicações culturais e sociais atraem há muito tempo o interesse de sociólogos e antropólogos. Festivais sempre têm um tema e possuem diversos estilos e programações, todos em busca de promover um tipo de experiência específica (GETZ, 2010).

Essas celebrações canalizam uma experiência intelectual, comportamental e emocional e, ao mesmo tempo, respostas emocionais potencialmente levadas a resultados inesperados e, às vezes, indesejados, em termos comportamentais e políticos. Para Getz (2010), muitos significados podem ser conectados à experiência de um festival, em nível pessoal, de grupos sociais e culturais, que devem ser vistos como construções sociais que variam de região para região ao longo do tempo.

Esses eventos celebram um sentimento relacionado ao local, por meio da organização de atividades inclusivas em ambientes específicos e seguros. Também 
ISSN: 1983-7151

fornecem um veículo para a comunidade hospedar seus visitantes e compartilhar de tais atividades, com representações de valores, interesses e aspirações.

Os festivais necessitam de espaços físicos maiores em áreas urbanas ou rurais, como florestas, próximo de rios, campos abertos, e ainda necessitam de conveniências feitas exclusivamente para eles; servem para entreter a população local, proporcionando atividades diferenciadas tanto dentro quanto fora da estação turística (YEOMAN et al., 2006). A cobertura da mídia feita durante os eventos ajuda as cidades a desenvolverem sua confiança e a gerarem uma imagem positiva no mercado turístico.

Litvin e Fetter (2006) destacam que as características festivas, lúdicas e celebrativas desses eventos são valorizadas em todo o mundo justamente por permitirem que os turistas conheçam as singularidades locais e compartilhem experiências coletivas. Para McKercher, Mei e Tse (2006), essas festas constituem oportunidade para mostrar a herança histórica do destino, as tradições locais e os aspectos étnicos. Autores como Douglas, Douglas e Derrett (2001) e Hall (1993) consideram que, ao permitir o contato com outras culturas, costumes e modos de vida, os festivais promovem uma maior compreensão à diversidade cultural.

Nesse contexto, Getz (2008) aponta a tendência da procura de diferentes experiências como fator que estimula a demanda por festivais, enquanto Prentice e Andersen (2003) destacam as necessidades de sociabilização e o crescimento das práticas voltadas ao lazer. Apoiados nas constatações de Chacko e Schaffer (1993), Getz (1991), Rolfe (1992) e Grant e Paliwoda (1998), Prentice e Andersen (2003) ressaltam que os eventos de artes e outras festas constituem um fenômeno em crescimento no setor do turismo mundial.

A realização de festivais, a partir da perspectiva do marketing turístico, tem se mostrado muito importante. Shin e Gwak (2008) afirmam que esses eventos desempenham vários papéis relevantes, como atrair turistas, construir a imagem do destino, animar comunidades e catalisar o desenvolvimento de outras atrações.

Felsenstein e Fleischer (2003) também afirmam que festivais são cada vez mais utilizados como instrumentos para promover o turismo e impulsionar a economia regional. Em seus estudos, Getz (1993) e Formica e Uysal (1998) 
mostram que o ganho econômico das festas pode ser substancial, a partir da oferta de atividades interessantes e das opções de gastos, tanto para a população local como para os turistas.

Ao comentar que festas e celebrações com apelo turístico são amplamente inseridas nas estratégias de marketing de diferentes nações, Stokes (2006) se refere a um fato que há muito vem sendo observado por estudiosos do tema, como Mules (1998) e Gnoth e Anwar (2000): a consolidação do turismo de eventos.

Essa definição, para Stokes (2006), implica uma abordagem estratégica, já que se observa, nos dias atuais, a tentativa de explorar esses eventos com objetivos comerciais e turísticos e criar deliberadamente novas atrações, enquadrandoas em estratégias de desenvolvimento turístico mais alargadas.

A explosão do número de festivais em todo o mundo é, segundo Prentice e Andersen (2003), multifacetada quanto à oferta (planejamento cultural, desenvolvimento do turismo cívico, reposicionamento do destino) e quanto à procura (lazer, necessidade de socialização, desejo de experiências criativas e de "fé" por parte de alguns segmentos de mercado).

McKercher, Mei e Tse (2006) afirmam que, em teoria, os festivais devem potencializar as atrações, que respondem pelo aumento da demanda pelo maior número de turistas e pela capacidade, referida por Derret (2004), de estender a alta temporada de turismo e até de criar "novas estações". Para aqueles autores, os festivais devem ser organizados de forma a proporcionar experiências de alta qualidade para aumentar os níveis de satisfação dos frequentadores.

A proliferação de festas e eventos pode ser uma consequência dos processos de reestruturação urbana, levando-se em conta que um condutorchave para o crescimento e reinvenção de festivais é o potencial capaz de oferecer uma série de resultados em termos de desenvolvimento econômico e de revitalização e/ou reposicionamento de destinos, sem falar na capacidade de absorção de investimentos no setor de turismo e, consequentemente, de geração de receitas (QUINN, 2009).

Em muitas cidades do mundo ocidental, a motivação fundamental para o desenvolvimento de estratégias nessa direção tem sido a recuperação, em longo prazo, dos quadros de declínio econômico. Mesmo para as cidades que tentam 
chegar ao palco global pela primeira vez, festivais e eventos fazem parte das estratégias de marketing local, especialmente quando movidas pela ideologia da globalização, da localização e da concorrência entre destinos (QUINN, 2009).

\section{METODOLOGIA}

Desde a perspectiva da metodologia científica, classifica-se o presente trabalho como uma pesquisa básica (quanto à natureza do estudo), quantitativa (quanto à abordagem do problema) e exploratória (quanto aos objetivos). Quanto aos procedimentos técnicos para a realização do trabalho, empregouse a pesquisa bibliográfica e a sondagem ou survey.

Para a coleta de dados, aplicou-se um questionário estruturadoe autopreenchível, composto por 31 perguntas fechadas, distribuídas entre as dimensões de análise e a identificação sociodemográfica dos entrevistados. A construção do instrumento teve como referências preliminares o estudo de Deng, Li e Shen (2013), composto por seis diferentes dimensões: administração, benefícios, estrutura, facilidades, serviços e tema. As alternativas de resposta basearam-se na escala de Likert de sete pontos ( 1 = discordo totalmente; 7 = concordo totalmente).

Para a seleção da amostragem, este estudo optou pelo método não probabilístico por conveniência. Consideram-se como universo deste estudo os frequentadores do festival, distribuídos em quatro dias de evento: quartafeira (20/3/2013), quinta-feira (21/3/2013), sexta-feira (22/3/2013) e sábado (23/3/2013). No total, foram utilizados 507 questionários/respondentes distribuídos nos quatro dias do festival. Utilizou-se questionário estruturado, autopreenchível, com perguntas abertas e fechadas.

O questionário aplicado com os participantes foi pré-testado com $10 \%$ da amostra, ou seja, 40 questionários com estudantes, a fim de identificar possíveis erros na montagem do instrumento survey. Após o pré-teste realizado, verificouse que nenhum erro foi encontrado, ou seja, a aplicação obteve êxito, o que permitiu continuar o estudo no Festival da Cerveja.

A realização do trabalho cumpriu as seguintes etapas: elaboração do questionário, pré-teste, aprovação do questionário, treinamento da equipe 
de 6 entrevistadores, coleta de dados, verificação, codificação e digitação das respostas, elaboração do relatório e apresentação das conclusões do estudo. Para a análise dos dados, utilizaram-se os softwares Microsoft Excel e Statistical Package for the Social Sciences (SPSS).

\section{ANÁLISE}

Para verificar a confiabilidade e a consistência interna dos construtos, utilizou-se a análise do Alfa de Cronbach. Também conhecido como indicador de veracidade dos dados, o Alfa de Cronbach analisa o grau de convergência das informações, ou seja, verifica o grau de concordância dos respondentes em relação a um construto teórico aplicado. Dessa forma, os índices superiores a 0,60 são considerados aceitáveis para validação da convergência interna da dimensão (CRONBACH, 1951).

Destaca-se que, neste estudo, gerou-se o índice de 0,901. Com base nas descrições de Cronbach (1951), Hair, Anderson, Tatham e Black (2005) e Malhotra (2001), esse escore possui alta validade para dar continuidade no estudo estatístico, pois os autores indicam que os Alphas de Cronbach devem ser acima de 0,50, 0,60 e 0,70 respectivamente.

A verificação da relação entre as escalas foi feita por meio da Modelagem de Equações Estruturais (MEE). Essa técnica, de acordo com Hair et al. (2005), combina os aspectos da análise fatorial e a regressão linear, com o intuito de verificar estatisticamente as possíveis relações entre os construtos.

Tal modelagem, de acordo com Gefen, Straub e Bordreau (2000), permite aos pesquisadores responderem questionamentos de uma forma sistemática e abrangente, pois, por meio da sua aplicação, é possível modelar, ao mesmo tempo, diversas dimensões e construtos, que podem ser dependentes ou independentes. Nesse sentido, Ullman (2006, p. 38) destaca a importância "quando o fenômeno de interesse é complexo e multidimensional, pois a MEE é a única técnica que permite o teste completo e simultâneo de todas as relações".

Gefen, Straub e Bordreau (2000) ainda justificam que sua aplicação representa a identificação de uma série de relações hipotéticas de causa- 
efeito entre as variáveis estudadas, ou seja, os relacionamentos dessa composição estatística são descritos pela magnitude do efeito - direta ou indiretamente - para as variáveis e dimensões de análise. Byrne (2009) relata que a Modelagem de Equação Estrutural é uma metodologia estatística que possui uma abordagem de confirmação para a análise de uma teoria estrutural sobre algum fenômeno. Usualmente, essa teoria representa um modelo causal, a partir do qual os processos podem gerar observações múltiplas de uma ou mais situações. A Figura 1 ilustra a Modelagem de Equação Estrutural adotada neste estudo.

Figura 1 - Modelagem de Equação Estrutural

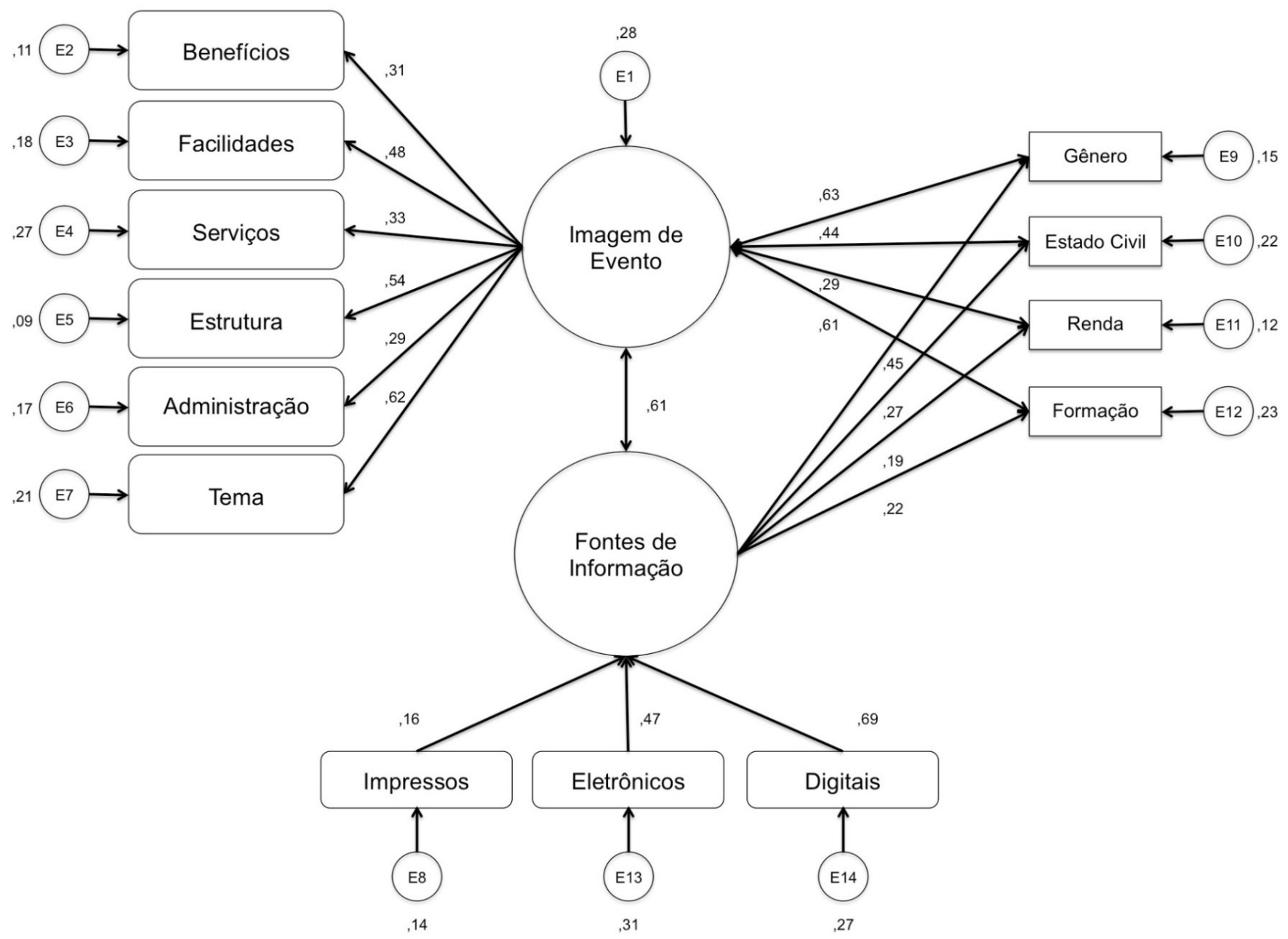

Fonte: Elaborada pelos autores.

Por meio das equações estruturais verifica-se que as fontes de informação exercem influência de $61 \%$ sobre a imagem de evento. 
Verificou-se que os meios digitais melhor representam as fontes de informação, com $69 \%$, ou seja, as redes sociais e outros portais do festival na internet impactaram mais o público na hora da divulgação do evento. Os meios eletrônicos, que englobam televisão, rádio e reportagens, representaram 47\%. Os meios impressos, que abrangem jornal, outdoor e panfletos/folder e cartaz, representaram 16\%.

A escala da Imagem de Evento é mais bem representada pelo Tema do Evento (62\%). Em seguida, a Estrutura do Evento teve maior representação (54\%). Logo atrás, com 48\%, a maior representação foi da dimensão Facilidade.

Dentro da escala de Fontes de Informação, a maior representatividade foi de Gênero (45\%). Essa mesma variável foi mais bem representada na escala de Imagem de Evento, com 63\%. Em seguida, na escala de Fontes de Informação, a maior representatividade se deu pelo Estado Civil (27\%), enquanto que a Formação (61\%) melhor representou a variável de Imagem de Evento. $\mathrm{Na}$ escala de Fontes de Informação, a Formação ficou em terceiro lugar de representatividade, com $22 \%$, enquanto o terceiro na escala de Imagem de Evento foi Estado Civil (44\%). Por fim, na escala de Fontes de Informação, a menor representação se deu pela Renda (19\%), que também foi a que menos representou a escala de Imagem de Evento, com 29\%.

Para realização da análise num contexto descritivo, agruparam-se as variáveis do construto nas seis dimensões teóricas estudadas: Benefícios; Facilidades; Serviços; Estrutura; Administração e Tema, conforme se observa na Tabela 1.

Tabela 1 - Frequência, porcentagens e médias das afirmações

\begin{tabular}{|c|c|c|c|c|c|c|c|c|c|}
\hline \multicolumn{1}{|c|}{ Afirmações e Notas } & \multicolumn{2}{c|}{$\begin{array}{c}1 \text { e 2 } \\
\text { Baixo }\end{array}$} & $\begin{array}{c}3-4-5 \\
\text { Médio }\end{array}$ & \multicolumn{2}{|c|}{$\begin{array}{c}6 \text { e 7 } \\
\text { Alto }\end{array}$} & Média \\
\hline & Q1 & $\begin{array}{c}\text { A visita ao festival satisfez a } \\
\text { minha curiosidade. }\end{array}$ & 11 & $2 \%$ & 100 & $20 \%$ & 396 & $78 \%$ & 6,15 \\
\cline { 2 - 10 } Benefícios & $\begin{array}{c}\text { A visita ampliou meu } \\
\text { horizonte, proporcionando- } \\
\text { me a oportunidade de } \\
\text { experimentar diferentes } \\
\text { culturas. }\end{array}$ & 17 & $3 \%$ & 114 & $22 \%$ & 376 & $74 \%$ & 5,88 \\
\cline { 2 - 10 } & Q14 & $\begin{array}{c}\text { Eu aprendo sobre novas } \\
\text { culturas ao visitar o Festival } \\
\text { da Cerveja. }\end{array}$ & 48 & $9 \%$ & 174 & $34 \%$ & 285 & $56 \%$ & 5,27 \\
\cline { 2 - 10 } & Q19 & $\begin{array}{c}\text { A visita ao festival aproxima } \\
\text { o relacionamento com meus } \\
\text { parentes e amigos. }\end{array}$ & 49 & $10 \%$ & 131 & $26 \%$ & 327 & $64 \%$ & 5,45 \\
\hline
\end{tabular}


ISSN: 1983-7151

\begin{tabular}{|c|c|c|c|c|c|c|c|c|c|}
\hline \multirow{5}{*}{ Facilidades } & Q2 & $\begin{array}{c}\text { O Festival da Cerveja possui } \\
\text { uma boa segurança. }\end{array}$ & 30 & $6 \%$ & 131 & $26 \%$ & 346 & $68 \%$ & 6,01 \\
\hline & Q4 & $\begin{array}{l}\text { Os pavilhões possuem } \\
\text { banheiros bons e limpos. }\end{array}$ & 33 & $7 \%$ & 152 & $30 \%$ & 322 & $63 \%$ & 5,78 \\
\hline & Q7 & $\begin{array}{l}\text { Os stands de cerveja } \\
\text { no festival são bons e } \\
\text { adequados. }\end{array}$ & 14 & $3 \%$ & 170 & $33 \%$ & 323 & $64 \%$ & 5,69 \\
\hline & Q9 & $\begin{array}{l}\text { As áreas de descanso no } \\
\text { festival são suficientes. }\end{array}$ & 15 & $3 \%$ & 138 & $27 \%$ & 354 & $70 \%$ & 5,54 \\
\hline & Q11 & $\begin{array}{l}\text { O festival está equipado } \\
\text { com um bom sistema de ar- } \\
\text { condicionado. }\end{array}$ & 8 & $3 \%$ & 112 & $22 \%$ & 387 & $76 \%$ & 5,70 \\
\hline \multirow{3}{*}{ Serviços } & Q3 & $\begin{array}{c}\text { As equipes de profissionais } \\
\text { do Festival da Cerveja são } \\
\text { bem preparadas. }\end{array}$ & 18 & $4 \%$ & 120 & $24 \%$ & 369 & $72 \%$ & 5,82 \\
\hline & Q15 & $\begin{array}{l}\text { Os serviços fornecidos no } \\
\text { festival são de alta qualidade. }\end{array}$ & 13 & $3 \%$ & 200 & $39 \%$ & 294 & $58 \%$ & 5,53 \\
\hline & Q18 & $\begin{array}{l}\text { Os atendentes do Festival } \\
\text { da Cerveja são simpáticos e } \\
\text { prestativos. }\end{array}$ & 5 & $1 \%$ & 159 & $31 \%$ & 343 & $68 \%$ & 5,92 \\
\hline \multirow{3}{*}{ Estrutura } & Q6 & $\begin{array}{l}\text { Os shows do festival são } \\
\text { atrativos e interessantes. }\end{array}$ & 30 & $6 \%$ & 170 & $34 \%$ & 307 & $61 \%$ & 5,51 \\
\hline & Q8 & $\begin{array}{c}\text { A variedade de cervejas é } \\
\text { bastante atrativa. }\end{array}$ & 4 & $1 \%$ & 53 & $10 \%$ & 450 & $89 \%$ & 6,46 \\
\hline & Q13 & $\begin{array}{c}\text { A variedade de cervejas } \\
\text { no festival não é atrativa. } \\
\text { (reversa) }\end{array}$ & 382 & $75 \%$ & 51 & $10 \%$ & 74 & $15 \%$ & 2,26 \\
\hline \multirow{3}{*}{ Administração } & Q10 & $\begin{array}{c}\text { É fácil comprar ingresso e } \\
\text { entrar no festival. }\end{array}$ & 52 & $10 \%$ & 182 & $36 \%$ & 273 & $54 \%$ & 6,16 \\
\hline & Q16 & $\begin{array}{l}\text { O espaço no pavilhão é } \\
\text { adequado para o fluxo de } \\
\text { visitantes. }\end{array}$ & 12 & $2 \%$ & 116 & $23 \%$ & 379 & $75 \%$ & 5,97 \\
\hline & Q20 & $\begin{array}{l}\text { As filas de espera nos guichês } \\
\text { são organizadas. }\end{array}$ & 18 & $4 \%$ & 69 & $14 \%$ & 420 & $83 \%$ & 5,16 \\
\hline \multirow{3}{*}{ Tema } & Q12 & $\begin{array}{l}\text { A divulgação do Festival da } \\
\text { Cerveja é ampla e eficaz. }\end{array}$ & 28 & $6 \%$ & 185 & $36 \%$ & 294 & $58 \%$ & 5,46 \\
\hline & Q17 & $\begin{array}{c}\text { A ideia do Festival da Cerveja } \\
\text { é inovadora e única. }\end{array}$ & 20 & $4 \%$ & 95 & $19 \%$ & 392 & $77 \%$ & 5,82 \\
\hline & Q21 & $\begin{array}{c}\text { O tema do festival é } \\
\text { adequado à cidade de } \\
\text { Blumenau. }\end{array}$ & 7 & $1 \%$ & 25 & $5 \%$ & 475 & $94 \%$ & 6,60 \\
\hline
\end{tabular}

Fonte: Dados da pesquisa de campo.

Hair et al. (2005) descrevem que a Correlação de Pearson é a maneira mais ampla utilizada para calcular as correlações ou as covariâncias entre variáveis manifestas. É a forma mais comum de correlação utilizada na análise multivariada, facilitando a computação das matrizes de correlação. 
Pestana e Gageiro (2003) afirmam que as correlações devem ser classificadas desta forma: valores menores que 0,2 indicam correlação muito baixa; entre 0,2 e 0,39, baixa; entre 0,40 e 0,69, moderada; entre 0,7 e 0,9, alta; e acima de 0,9, muito alta. A Tabela 2 mostra as correlações entre idade e gênero.

Tabela 2 - Correlações entre idade e gênero

\begin{tabular}{|c|c|c|}
\hline \multirow{2}{*}{ Construto e dimensões } & \multicolumn{2}{|c|}{ Correlações de Pearson com: } \\
\cline { 2 - 3 } & Idade & Gênero \\
\hline Benefícios &, 0456 &, 0989 \\
\hline Sig (bicaudal) &, 305 &, 026 \\
\hline Facilidade &, 1165 &, 470 \\
\hline Sig (bicaudal) &, 009 &, 1009 \\
\hline Serviço &, 0382 &, 023 \\
\hline Sig (bicaudal) &, 391 &, 0490 \\
\hline Estrutura &, 0029 &, 271 \\
\hline Sig (bicaudal) &, 949 &, 0036 \\
\hline Administração &, 1148 &, 935 \\
\hline Sig (bicaudal) &, 010 &, 0687 \\
\hline Tema &, 0706 &, 122 \\
\hline Sig (bicaudal) &, 112 &, 0742 \\
\hline Construto &, 0866 &, 095 \\
\hline Sig (bicaudal) & 051 & \\
\hline
\end{tabular}

Fonte: Dados da pesquisa de campo.

Hair et al. (2005) defendem que a aplicação da análise fatorial serve como um modelo de mensuração das relações entre os indicadores e os fatores do construto. Além disso, a proposição do tratamento estatístico deve reduzir o tamanho original, ou seja, deverá fornecer base para criação de um novo conjunto de variáveis que possa incorporar o caráter e a natureza do original em um número menor de questões.

Nesta pesquisa, optou-se pela aplicação estatística no construto de Imagem de Evento, pois, como afirmam os autores do estudo, o instrumento deve ser reduzido com o intuito de ter-se um construto que possa medir a imagem dos indivíduos de acordo com cada realidade a ser aplicada.

Dois testes foram realizados para verificar a possibilidade da sua aplicação: Teste Kaiser - Meyer-Olklin (KMO) e Bartlett (BTS). O primeiro (KMO) apresentou o valor de 0,801. Hair et al. (2005) defendem que os valores devem ultrapassar 0,70 como um índice mínimo aceitável. Já o teste BTS apresentou 2602,6 e $p=0,000$. Ambos demonstraram validade para a continuidade da aplicação. 
Para isso, utilizou-se a análise fatorial exploratória por meio de componentes principais e com rotação varimax normalizada. Este trabalho seguiu dois critérios: extração dos fatores com autovalores maiores que um e comunalidades maiores que 0,50 . Nenhuma variável foi retirada na aplicação, pois todas seguiram as comunalidades maiores que as estabelecidas pelo critério do trabalho.

A Tabela 3 apresenta a matriz rotada da análise fatorial, na qual todas as afirmativas foram superiores aos critérios estabelecidos por Hair et al. (2005), pois ultrapassaram comunalidades maiores que 0,50. Destaca-se que as variáveis Q6, Q12, Q13 e Q21 foram excluídas do construto por apresentarem fatores menores do que 0,50 .

Tabela 3 - Análise Fatorial do construto de imagem de evento

\begin{tabular}{|c|c|c|c|c|}
\hline \multicolumn{2}{|r|}{ Variáveis } & Fator 1 & Fator 2 & Fator 3 \\
\hline Q1 & A visita ao festival satisfez a minha curiosidade. & 0,2186 & 0,1334 & 0,6947 \\
\hline Q2 & O Festival da Cerveja possui uma boa segurança. & 0,1817 & 0,3572 & 0,5537 \\
\hline Q3 & $\begin{array}{l}\text { As equipes de profissionais do Festival da Cerveja são bem } \\
\text { preparadas. }\end{array}$ & 0,3111 & 0,1447 & 0,6158 \\
\hline Q4 & Os pavilhões possuem banheiros bons e limpos. & 0,2077 & 0,2686 & 0,6105 \\
\hline Q5 & $\begin{array}{l}\text { A visita ampliou meu horizonte, proporcionando-me a } \\
\text { oportunidade de experimentar diferentes culturas. }\end{array}$ & 0,5949 & 0,0537 & 0,4590 \\
\hline Q7 & Os stands de cerveja do festival são bons e adequados. & 0,3794 & 0,1137 & 0,5641 \\
\hline Q8 & A variedade de cervejas é bastante atrativa. & 0,1283 & 0,1535 & 0,6855 \\
\hline Q9 & As áreas de descanso no festival são suficientes. & 0,1215 & 0,7842 & 0,0744 \\
\hline Q10 & É fácil comprar ingresso e entrar no festival. & 0,0059 & 0,5370 & 0,4200 \\
\hline Q11 & $\begin{array}{l}\text { O festival está equipado com um bom sistema de ar- } \\
\text { condicionado. }\end{array}$ & 0,0783 & 0,7981 & 0,1964 \\
\hline Q14 & $\begin{array}{l}\text { Eu aprendo sobre novas culturas ao visitar o Festival da } \\
\text { Cerveja. }\end{array}$ & 0,7495 & 0,1234 & 0,1409 \\
\hline Q15 & Os serviços fornecidos no festival são de alta qualidade. & 0,5776 & 0,2965 & 0,3828 \\
\hline Q16 & O espaço no pavilhão é adequado para o fluxo de visitantes. & 0,2322 & 0,7144 & 0,1989 \\
\hline Q17 & A ideia do Festival da Cerveja é inovadora e única. & 0,7017 & 0,1683 & 0,1689 \\
\hline Q18 & $\begin{array}{c}\text { Os atendentes do Festival da Cerveja são simpáticos e } \\
\text { prestativos. }\end{array}$ & 0,5724 & 0,2220 & 0,2925 \\
\hline Q19 & $\begin{array}{l}\text { A visita ao festival aproxima o relacionamento com meus } \\
\text { parentes e amigos. }\end{array}$ & 0,5949 & 0,0519 & 0,2014 \\
\hline Q20 & As filas de espera nos guichês são organizadas. & 0,4148 & 0,5714 & 0,1612 \\
\hline
\end{tabular}

Fonte: Dados da pesquisa de campo 
A partir da matriz rodada e das significâncias das variáveis dentro dos fatores do construto, foram nomeados os conjuntos. O primeiro, denominado Valor Agregado, é representado por seis questões e engloba as variáveis Q5, Q14, Q15, Q17, Q18 e Q19. Esse fator indica os valores adquiridos durante a experiência no festival, tanto culturalmente como valores pessoais.

Já o segundo fator, formado por cinco afirmações, compreende as variáveis: Q9, Q10, Q11, Q16, Q20 e é nomeado Comodidade. Nesse conjunto se enquadram as afirmações que são relacionadas às áreas do evento usufruídas pelos visitantes.

Por fim, o terceiro fator é formado por outras seis questões: Q1, Q2, Q3, Q4, Q7 e Q8 e nomeado de Infraestrutura, sendo compreendido como qualidade dos serviços prestados dentro do festival.

A partir da extração e da exposição dos fatores adquiridos pela análise fatorial, a Tabela 4 apresenta os grupos de variáveis e as suas respectivas confiabilidades de estudo.

Tabela 4 - Variáveis e alfa de Cronbach para cada fator

\begin{tabular}{|c|c|c|}
\hline Fatores & Variáveis & Alfa de Cronbach \\
\hline 1 & Valor Agregado &, 802 \\
\hline 2 & Comodidade &, 795 \\
\hline 3 & Infraestrutura &, 800 \\
\hline
\end{tabular}

Fonte: Dados da pesquisa de campo.

Na Tabela 4 foram calculados os alfas de Cronbach para cada fator e percebeuse que todos possuíram boa confiabilidade e ultrapassaram os níveis aceitáveis: 0,70 como considerados por Hair et al. (2005); e 0,60, indicados por Malhotra (2001). Diante disso, a Tabela 5 apresenta os dados descritivos dos três fatores extraídos da análise.

Tabela 5 - Resultados descritivos dos grupos extraídos da análise fatorial

\begin{tabular}{|c|c|c|c|c|}
\hline \multicolumn{2}{|c|}{ Fatores } & Mínimo & Máximo & Média \\
\hline 1 & Valor Agregado & 1 & 7 & 5,700 \\
\hline 2 & Comodidade & 1 & 7 & 5,712 \\
\hline 3 & Infraestrutura & 1 & 7 & 5,989 \\
\hline
\end{tabular}

Fonte: Dados da pesquisa de campo. 
A Tabela 5 retrata as médias encontradas nos três fatores da análise. É possível perceber que o fator Infraestrutura teve média mais relevante do que os outros fatores, com 5,989. O fator Comodidade apresentou a média 5,712, enquanto que o Valor Agregado expressou a média 5,700.

\section{CONSIDERAÇÕES FINAIS}

Com a análise da pesquisa pôde-se perceber que o público está bastante satisfeito com o festival, porém existem algumas variáveis que devem ser revistas pelos organizadores do evento, como, por exemplo, diminuir as filas; melhorar a qualidade dos serviços, a atratividade de shows; facilitar ainda mais a compra de ingressos e reforçar mais a divulgação para que a imagem melhore a cada edição e que o evento se torne a cada ano mais conhecido, visto que é relativamente novo na cidade e nem todos os habitantes o conhecem.

Com os resultados foi possível observar que as mulheres avaliaram as dimensões do construto mais positivamente do que os homens e as médias entre as dimensões ficaram muito próximas. Como esperado, a dimensão Tema teve a maior média entre eles, pois o Tema Cerveja combina com a cidade, visto que a região é conhecida pelas suas cervejarias artesanais e Blumenau é conhecida como a "Capital da Cerveja" em virtude da Oktoberfest.

Por meio da análise fatorial de caminhos-ou Modelagem de Equação Estrutural -, verificou-se que as Fontes de Informação exercem influência sobre a Imagem de Evento. A dimensão Tema é a que melhor representa a escala de Imagem de Evento e os Meios Digitais melhor representam as Fontes de Informação. As dimensões Benefício e Serviço tiveram maior relação com Gênero, enquanto Facilidade e Administração demonstraram maior correlação com Idade. As variáveis Estrutura e Tema não tiveram correlações com Idade e Gênero.

De acordo com a pesquisa e os dados multivariados, constatou-se que as mídias digitais, se analisadas juntas (Redes Sociais e outros portais na internet: Blog e Site), tiveram grande impacto na divulgação do evento, mas os meios de comunicação convencionais ainda têm mais poder na hora de divulgar o festival, como a televisão e o jornal. 
Por fim, é possível afirmar que os homens demonstraram estar mais satisfeitos do que as mulheres. As classes econômicas $A$ e $B$ ficaram mais satisfeitas do que as classes $C$, D e $E$, e os casados foram mais satisfeitos do que os solteiros, separados e viúvos.

Recomenda-se, para futuros estudos acadêmicos sobre eventos, que seja aplicada a metodologia qualitativa no Festival Brasileiro da Cerveja, a fim de se obter maior profundidade nos dados e nas informações que se relacionam com sentimentos, razões e emoções das pessoas perante o evento.

Por meio da Análise Fatorial reduziu-se a escala do construto e, a partir disso, aconselha-se que a nova escala seja aplicada nas próximas edições do Festival da Cerveja para que se identifique a validade da análise fatorial. Sugere-se, ainda, que seja replicado esse estudo em outros festivais ou eventos, com o intuito de identificar as percepções e os níveis de satisfação com outros perfis de usuários.

Como contribuição, podem ser destacados os resultados encontrados na imagem do evento. Os dados quantitativos proporcionaram análises descritivas sobre o público que frequenta o evento e pôde-se perceber que os visitantes estão bastante satisfeitos com o festival. Os resultados da pesquisa possibilitam a melhoria do evento no futuro e servem de base para focar ainda mais o público-alvo que frequenta o festival.

Apesar de o festival apresentar uma imagem positiva perante o público, vale destacar que algumas variáveis, mesmo com médias altas, podem ser melhoradas em edições futuras, no caso, questões que alcançaram menos de $70 \%$ de respostas altas podem ser melhorados nas próximas edições, como, por exemplo, melhorar a limpeza dos pavilhões, diminuir as filas de espera nos guichês, facilitar ainda mais a compra de ingressos.

Além de focar nas melhorias estruturais do evento, os organizadores do festival podem utilizar os resultados da pesquisa para analisar quais meios de comunicação foram mais eficazes na hora de divulgação para focar nas mídias que mais impactam o público que frequenta o evento. 
ISSN: 1983-7151

REFERÊNCIAS

BYRNE, D. The Sage Handbook of case-based methods. London: Sage Publications, 2009.

CHACKO, H. \& SCHAFFER, J. The evolution of a festival. Tourism Management, v 14(4), p 475-482, 1993.

CHIEN, P. H. M.; CORNWELL, T. B.; \& STOKES, R. A theoretical framework for analysisof image transfer in multiple sponsorships. Paper presented the meeting of ANZMAC 2005 conference, Perth, Australia, 2005.

DENG, C.Q.; LI, M. \& SHEN, H. Developing a measurement scale for event image [Versão eletrônica]. Journal of Hospitality \& Tourism Research, 2013.

CRONBACH, L. J. Coefficient alpha and the internal structure of tests. Psychometrika, 16(3), 297-334, 1951.

DERRET, R. Festivals, events and the destination. In I. Yeoman, M. Robertson, \& J. Ali-Knight (Ed). Festival and events management. Elsevier Butterworth-Heinemann, London, 2004.

DOUGLAS, N.; DOUGLAS, N. \& DERRETT, R. Special interest tourism: studies and cases. Brisbane: John Wiley \& Sons, 2001.

FELSENSTEIN, D. \& FLEISCHER, A. Local festivals and tourism promotion: the role of public assistance and visitor expenditure. Journal of Travel Research, v 41(4), p 385-392, 2003.

FERRAND, A. \& PAGES, M. Image sponsoring: a methodology to match event and sponsor. Journal of Sport Management, v 10(3), p 278-291, 1996.

FLOREK, M. \& INSCH, A. When fit matters: leveraging destination and event image congruence. Journal of Hospitality Marketing e Management, v 20(3), p 265-286, 2011.

FORMICA, S. \& UYSAL, M. Market segmentation of an international cultural historical event in Italy. Journal of Travel Research, v 36(4), p 16-24, 1998.

GEFEN, D.; STRAUB, D.; BOUDREAU, M. C. Structural equation modeling and regression: guidelines for research practice. Communications of AIS, v 4(7), p 1-80, 2000.

GETZ, D. Festivals, special events, and tourism. NewYork: Van Nostrand Rheinhold, 1991.

.Corporate culture in not-for-profitfestival organizations. Journal Festival Management and Event Tourism, v 1(1), p 11-17, 1993. 
.Event management and event tourism. 2nd ed. New York: Cognizant Communications Corporation, 2004.

. Event tourism: definition, evolution, and research. Tourism Management, v 29(3), p 403-428, 2008.

. The nature and scope of festival studies. International Journal of Event Management Research, v 5(1), p 1-47, 2010.

GNOTH, J. \& ANWAR, S. New Zealand bets on event tourism. Cornell Hotel and Restaurant Administration Quarterly, p 72- 83, 2000.

GRANT, D. \& PALIWODA, S. Segmenting arts and festival consumers: overview of the arts consumer. Festival Management \& Event Tourism, v 5(4), p 207-220, 1998.

GÜRSOY, D.; KIM, K. \& UYSAL, M. Perceived impacts of festivals and special events by organizers: an extension validation. Tourism Management. v 25(2), 171-18, 2004.

GWINNER, K. A model of image creation and image transfer in event sponsorship. International Marketing Review, v 14(3), p 145-158, 1997.

HAIR, Joseph F.; ANDERSON, R. E.; TATHAM, R. L. \& BLACK, W. C. Análise multivariada de dados. 5. ed. Porto Alegre: Bookman, 2005.

HALL, C. M. Hallmark tourist events: impacts management and planning. London: Belhaven, 1993.

LI, X. \& VOGELSONG, H. Comparing methods of measuring image change: a case study of a small scale community festival. Tourism Analysis,v 10(4), p 349-360, 2006.

LITVIN, S. W., \& FETTER, E. Can a festival be too successful?: a review of Spoleto, USA. International Journal of Contemporary Hospitality Management, v 18(1), p 41-49, 2006.

MALHOTRA, N. K. Pesquisa de marketing. 3a ed. Porto Alegre: Bookman, 2001.

MARTÍN, H. S., \& BOSQUE, I. A. R. Exploring the cognitive-affective nature of destination image and the role of psychological factors in its formation. Tourism Management, $v$ 29(2), p 263-277, 2008.

MCKERCHER, B., MEI, W., \& TSE, T. Are short duration festivals tourist atractions? Journal of Sustainable Tourism, v 14(1), p 55-66, 2006.

MULES, T. Events tourism and economic development in Australia. In D. Tyler, Y. Guerrier, \& A. Robinson (Ed). Managing tourism in cities: policy, processes and practice (pp. 195-214). Chichester: John Wiley \& Sons, 1998. 
PESTANA, M. H. \& GAGEIRO, J. N. Análise de dados para ciências sociais: a complementaridade do SPSS. 3. ed. Lisboa: Silabo, 2003.

PRENTICE, R., ANDERSEN, V. Festival as a creative destination. Annals of Tourism Research, v 30(1), p 7-30, 2003.

QUINN, B. Festivals, events, and tourism. In: T. Jamal, \& M. Robinson (Ed.). The Sage handbook of tourism studies (pp. 483-503). London: Sage, 2009.

RIFON, N. J., CHOI, S. M., TRIMBLE. C. S., HAIRONG, L. Congruence effects in sponsorship: the mediating role of sponsor credibility and consumer attributions of sponsor motive. Journal of Advertising, v 33(1), p 29-42, 2004.

ROLFE, H. Arts festivals in the UK. London: Policy Studies Institute, 1992.

ROY, D., \& CORNWELL, B. The effects of consumer knowledge on responses to event sponsorships. Psychology \& Marketing, v 21(3), p 185-207, 2004.

SCHIFFMAN, L., \& KANUK L. Consumer behavior. 10th edition. Upper Saddle River, NJ: Prentice-Hall, 2010.

SCHUSTER, J. M. Ephemera, temporary urbanism and imaging. In L. J.; Vale, \& S. B. Warner (ED) Imaging the city: continuing struggles and new directions (pp. 361-396). New Brunswick, NJ: CUPR Books, 2001.

SHIN, Y., \& GWAK, H. Segmenting visitors to cultural festival: an example in Gwangju, Korea. Tourism Today, v 8, p 100-117, 2008.

STOKES, R. Network-based strategy making for events tourism. European Journal of Marketing, v 40(5-6), p 682-695, 2006.

ULLMAN, J. B. Structural equation modeling: reviewing the basics and moving forward. Journal of Personality Assessment, 87(1), 35-50, 2006.

WEEKS, C. S.; CORNWELL, T. B. \& DRENNAN, J. C. Leveraging sponsorships on the internet: activation, congruence, and articulation. Psychology \& Marketing, v 25(7), 637-654, 2008.

XING, X. \& CHALIP, L. Effects of hosting a sport event on destination brand: atest of cobranding and match-up models. Sport Management Review, v 9(1), 49-78, 2006.

YEOMAN, I.; ROBERTSON, M. \& ALI-KNIGHT, J. Gestão de festivais e eventos: uma perspectiva internacional de artes e cultura. São Paulo: Roca, 2006. 